\title{
Diffraction imaging for seal evaluation using ultra high resolution 3D seismic data
}

\author{
Alexander Klokov ${ }^{1}$, Ramón H. Treviño ${ }^{1}$, Timothy A. Meckel ${ }^{1}$ \\ 1 \\ 'Bureau of Economic Geology, The University of Texas at Austin
}

(October 7, 2016)

Running head: Diffraction imaging with P-Cable data

\begin{abstract}
Cap rock is any impermeable or low permeability formation that may trap oil, gas or water, preventing it from migrating to the surface. Evaluation of sealing properties of the cap rock is a critical task for seismic exploration. It is important for oil and gas prospecting as well as for locating reservoirs appropriate for carbon dioxide storage. The latter has been proposed as one solution to global climate change caused by heat-trapping anthropogenic gasses in the atmosphere. A fluid escaped from the reservoir fills voids in the overlying strata thereby causing local changes of acoustic properties. We aim to explore such fluid-saturated areas and thus evaluate sealing properties of underlying cap rocks. We assume that local acoustic impedance changes caused by fluid migration generate seismic diffractions. We isolate diffracted waves from P-Cable seismic data acquired over the area of interest and perform diffraction analysis of the near-surface interval (above $200 \mathrm{~m}$ ).
\end{abstract}

In the diffraction image obtained, we interpret an extensive system of broad sinuous channels, narrow linear faults, and diffuse fracture networks. In addition, we detect highdiffractivity anomalies, which extend vertically and laterally. We note no evidence of these 
anomalies in a conventional seismic image and associated seismic attribute (similarity and fracture density) volumes. We associate this high diffractivity to a variable pore fluid composition and saturation, which we infer to be due to hydrocarbon migration from the underlying strata. Consequently, we conclude poor seal quality for the underlying cap rocks.

During data processing, we test diffraction focusing analysis for velocity model building. This option appears quite valuable for P-Cable data processing because of short offset and limitations of the standard velocity analysis. 


\section{INTRODUCTION}

In addition to determining reservoir properties, a critical task for seismic exploration is evaluation of cap rock sealing properties. A reservoir with high porosity and permeability remains brine-saturated if the overlying top seal is not capable of retaining migrating fluids (e.g., hydrocarbons or carbon dioxide - $\mathrm{CO}_{2}$ ). In contrast, impermeable rock facies above a reservoir may form part of a trap that allows for accumulation and retention of fluids in the reservoir for a significant time. Consequently, such reservoir-seal scenarios are desirable in oil and gas exploration as well as for locating proper storages sites for anthropogenic $\mathrm{CO}_{2}$.

The sealing capacity of a cap rock is determined by a combination of various factors. The potential of the fluid to displace into the cap rock is related to capillary properties of the seal (Hubbert, 1953). In general, low permeability facies (e.g., mudstone, shale) comprise high quality seals because their high capillary entry pressure, which inhibits fluid migration into the seal facies. In contrast, sandstone has much lower capillary entry pressure and weaker resistance to fluid pressure (Schowalter, 1979). However, in some cases, a reservoir can be sealed by sandstone (Edlmann et al., 2016). Carbonates can be as highly-penetrable or a reliable seal depending on composition (Ahr, 2008).

Structural factors also affect seal quality. Faulting and fracturing can significantly increase the permeability of the rocks and can decrease sealing capacity. A fault can be sealing or non-sealing depending on the displacement pressure of the fluids and lithologies in contact at the fault (Smith, 1966; Antonellini and Aydin, 1994). The fault is sealing for lateral migration across the plane or vertical migration along the plane if the capillary entry pressure of the fault-zone material is greater than the fluid buoyancy displacement pressure. In contrast, the fault is non-sealing if filled by material with low capillary entry 
pressure, possibly accompanied by fractures.

If a cap rock is not capable of retaining buoyant fluids, they migrate vertically. The fluids saturate overlying strata thereby locally changing acoustic impedance. The local acoustic impedance contrasts manifest as seismic diffractions, which are an inherent part of the seismic wavefield. Diffraction waves generated by subtle subsurface features (like fluid-filled fractures) have relatively low amplitudes and are, consequently, typically suppressed by the stronger primary reflection waves. This is a major reason why seismic diffractions are not widely used in seismic exploration. However, if diffraction energy is purposely isolated and processed separately from reflections, diffractions can reveal valuable information about fluid saturation across an area (Klokov et al., 2015). Indeed, seismic diffractions may be applied to the characterization of fault planes and prediction of fluid-migration paths (Ogiesoba et al., 2015).

We propose using diffractivity analysis to evaluate the sealing capability of potential cap rocks by analyzing a $3 \mathrm{D}$ seismic dataset that was acquired by a novel ultra-high resolution system known as P-Cable (Petersen et al., 2010; Plaza-Faverola et al., 2011; Brookshire et al., 2015; Meckel and Mulcahy, 2016). We attempt to identify faulting/fracturing and evidence of fluid migration, which could be associated with fluid escaped from the underlying strata (below $3000 \mathrm{ft}$ ). To distinguish hydrocarbon from brine, we accompany seismic diffractions with wireline well logs recorded across the interpreted intervals.

The P-Cable technology utilizes short streamers separated by short crossline streamer spacing (Lippus, 2014). In combination with small shooting intervals (e.g. $12.5 \mathrm{~m}$ ), this strategy allows processing with extremely small bin sizes $(6.25 \mathrm{~m})$, which yields a fourfold increase in lateral resolution (typical bin size of conventional 3D marine surveys is $25 \mathrm{~m}$ ). 
In addition, P-Cable near-offset configuration provides the required fold with no need for an NMO correction for far offset, which allows preserving the high frequency content produced by special sources. Seismic diffractions have been proposed in the geophysical literature as a strategy for high-resolution seismic imaging (Landa, 2013; Sturzu et al., 2014; Benfield et al., 2016). Therefore, by applying diffraction imaging to P-Cable data, we combine a high-resolution method and high-resolution data.

\section{GEOLOGICAL SETTINGS}

The P-Cable dataset used in this study (43 sq. km) was acquired in Texas State Waters less than $16 \mathrm{~km}$ (10 miles) offshore from Bolivar Peninsula along the inner shelf of the upper Texas coast (Figure 1). The geologic section examined (generally above $300 \mathrm{~m}$ ) corresponds to mostly Quaternary age sediments as the top of the Miocene is reliably interpreted at a depth of approximately $425 \mathrm{~m}$ within the dataset coverage area. Meckel and Mulcahy (2016) described two Quaternary age incised valley systems and their adjacent interfluve areas. The systems were interpreted using another HR3D seismic survey located approximately 55 km (35 miles) southwest of the current survey. Although, seismic amplitude facies are not interpreted as part of the current study, it is assumed that facies similar to those interpreted by Meckel and Mulcahy (2016) are also present in the current study area.

The main structural feature that affects the geologic section of the current P-Cable dataset is the early Miocene Clemente-Tomas fault zone (Galloway, 1989; Bradshaw and Watkins, 1994; McDonnell et al., 2009), whose fault trace is northwest of the dataset. Consequently, the dataset examines a portion of the fault zones hanging well. Structural features interpreted in the current study are related to hanging well deformation. 


\section{DATA ACQUISITION AND PROCESSING}

The P-Cable acquisition system utilized 12 streamers, with $12.5 \mathrm{~m}$ crossline spacing and 8 channels each. The source-receiver offset did not exceed $110 \mathrm{~m}$. Shot point separation of $12.5 \mathrm{~m}$ allowed processing with bin size of $6.25 \mathrm{~m}$. Seismic energy was produced by a single 90 cubic inch generator-injector (GI) air gun source. The seismic data were recorded for $3 \mathrm{~s}$ with a sample rate of $0.5 \mathrm{~ms}$ and contained frequencies up to $250 \mathrm{~Hz}$ with a dominant frequency of $150 \mathrm{~Hz}$.

The data processing was performed at The University of Texas at Austin and included time correction for gun delay, shot signature deconvolution, geometrical spreading compensation, ensemble equalization to compensate shot-to-shot RMS amplitude variation, multiple attenuation, and noise removal. Finally, the data were restructured to common-midpoint gathers and stacked to produce a 3D data volume.

\section{VELOCITY MODEL BUILDING}

Velocity model building is a critical step in data processing that affects seismic image quality; inaccurate velocities cause defocusing of migrated images and lead to incorrect positioning of geologic objects. In surface seismic, the common practice is to derive velocity information from curvatures of reflection events (normal moveout). Seismic reflections are recorded by an extended array of receivers, and the receiver stations register a reflected wave with specific time delays that form hyperbolic reflection events in gathers. The time shifts (or the hyperbola curvatures) are associated with velocities in the strata that enable inversion of the velocity information. Greater number of receivers and longer offsets favor more accurate and robust velocity estimation. Because of short offsets in P-Cable acquisitions, traditional velocity analysis is challenging. Therefore, the common practice is to utilize 
velocity information from conventional seismic data in the same geographic area (Petersen et al., 2010) or assume a constant velocity model (Kluesner and Brothers, 2016; Singhroha et al., 2016).

The velocity model's impact on the quality of seismic imaging is particularly noticeable in images of scattering objects (Zhu et al., 1998) like small faults, voids, and local lithological heterogeneities. If the migration velocity is correct, diffracted energy is focused on a scatterer. If the velocity used is too low, the scattering object appears undermigrated and diffraction energy is smeared along a hyperbola with tails oriented downwards (towards larger times/depths). Migration velocities that are too high yield overmigrating of the scattering object, and the hyperbola tails are oriented upwards (towards smaller times/depths). This focusing/defocusing feature is observable even after single-offset migration that makes diffraction focusing analysis an option for velocity model building based on short-offset P-Cable data.

To construct a velocity model for our P-Cable dataset, we selected one inline section and migrated it with a set of constant-velocity models, varying from 1500 to $2500 \mathrm{~m} / \mathrm{s}$. Next, we performed diffraction imaging for each migrated section (the applied diffraction imaging approach is described below). After that, we scanned all diffraction images obtained for visual inspection and selected migration velocities providing the best focusing of scatterers. Assuming minimal lateral variations, we compiled all the selected velocities and generated a one-dimensional profile (Figure 2), which was appropriate for time migration.

The improvement in imaging associated with the velocity model optimization can be observed in Figure 3. It compares a diffraction image obtained after migration with a constant velocity model $(1520 \mathrm{~m} / \mathrm{s})$ and a diffraction image produced by migration with 
the optimized velocity. Note that the optimized velocity model provides better focusing of the point scatterers (zoomed panels on the right side of the figures).

Typically, many diffractors can be located in the subsurface. Provided that the diffraction response is not too corrupted by noise, a dense velocity model may be constructed based on diffraction focusing analysis (Sava et al., 2005; Fomel et al., 2007). In the current study, however, we found it reasonable to settle for the one-dimensional velocity profile because the near-surface of the study area is composed of relatively horizontal strata. In addition, accurate spatial location of subsurface features was not our goal (as it would have been for targeted drilling). Instead, our focus was to identify the area's possible fluid flux and, specifically, to identify potential migration pathways.

After the velocity profile was complete, the optimized velocity model was used to migrate the entire 3D P-Cable dataset, which was followed by diffraction imaging, described below.

\section{DIFFRACTION ANALYSIS}

For diffraction imaging, we separated diffractions in the migrated dip-angle domain (Klokov and Fomel, 2012). This approach allows segregating diffractions from background noise, which favors working with subtle scattering objects like fractures. The diffractions were separated in the time domain and subsequently converted to depth (using the developed velocity function) for direct correlating with wireline logs. The depth-converted 3D diffraction image had a sample

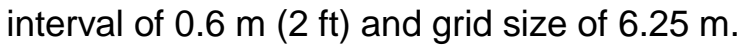

In contrast to commonly used seismic attributes like curvatures, coherence or similarity, a diffraction image characterizes each geologic object with amplitude, which is associated with acoustic impedance contrast. Thus, amplitudes resulting from diffractions are valuable for interpreting data. To facilitate interpretation, we converted the diffraction image into 
the diffraction energy attribute volume (Figure 4a).

Evaluation of diffraction power across the section revealed depth intervals in which diffractivity varied significantly. In the following, we examine each of these intervals separately. We compare the diffraction image with the conventional reflection seismic image and seismic attributes, which are routinely used for interpretation of reflector dislocations. In particular, we address similarity, which is a response of coherency between nearby traces (de Rooij and Tingdahl, 2002). In this work, similarity was calculated by the OpendTect environment with full dip-steering, extension in all directions, stepout equal one for both inline and crossline directions, and depth gate of $8 \mathrm{~m}$. In addition, we operated with the fracture density attribute (maximum curvature was used as the input; a radius of scanning was set to $100 \mathrm{~m}$ ). The attributes were calculated from an input conventional seismic image first obtained in the time domain and then converted to depth. Note that the P-Cable data acquisition was affected by a production platform that caused the shadow area observable in multiple depth slices and sections. The shallowest part of the geologic section, which contains the strongest diffraction amplitudes, is strongly affected by acquisition footprints. Therefore, we exclude it from the diffraction analysis, and examine only depths below $50 \mathrm{~m}$.

The strongest diffractions are located above $120 \mathrm{~m}$ (Figure 4). This interval is interpreted as a fluvial depositional system; a number of pronounced channel features are visible in the P-Cable seismic image (Figure 5b). A pronounced lithology contrast is often characteristic of a fluvial channel; note that the spontaneous potential log characterizes this interval with sharp changes in shale content across the sequence (Figure 4). Such lithologic contrast is often associated with strong acoustic impedance contrast, which, in turn, exhibits high diffractivity. In addition, fluvial channels tend to contain coarse grained sediments, thereby, creating a high-quality reservoir. When saturated with fluid, such reservoirs exhibit even 
higher diffractivity features. Figure 5a shows a horizon slice extracted from the diffraction energy volume. The channels (some are indicated by yellow arrows) appear sources of strong diffraction energy. Section view reveals that diffractions are concentrated along two laterally extended intervals connected by faults (Figure 4), which favor fluid migration. Figure 6 shows diffraction energy attribute extracted along three faults interpreted in Figures 4 and 5. Generally, the faults are associated with strong diffractions which indicates fluid leaking along the planes. Variations of diffraction power allows locating zones with higher permeability — for instance, west (right) part of the fault F1 reveals higher values of the diffraction energy attribute. The two high-diffractivity intervals are characterized by low electrical resistivity, which suggests brine not hydrocarbon saturation. Also note, that diffractivity decreases as the distance from the borehole increases - diffraction clusters appear much weaker between crosslines 0 and 500 indicating lower fluid content at far distances.

Diffraction strength drops significantly in the interval below $120 \mathrm{~m}$ depth, which contains vertically oriented scattering features (Figure 7). One group of these vertical scatterers (indicated by red arrows) represents faults, which have strong diffractivity and, because of the prominent vertical offset, are easily detectable in the conventional seismic image (Figure 8) and attribute sections (Figure 9). Another group of vertical scatterers (some are indicated by small green arrows) reveal much lower diffraction energy and are not associated with any vertical amplitude offset, which makes them undetectable using seismic attribute analysis based on reflections (Figure 9). The geometrical considerations suggest that the latter group of vertical scatterers are subseismic throws (or, possibly, fracture corridors) located in areas between the faults. Note that the subseismic throws are well-focused in the diffraction image (Figure 7b), which suggests a correct migration velocity model developed 
(inaccuracies in migration velocity lead to smearing of scattering objects).

In Figures 10-13, we examine inline 300, south of the shadow zone caused by the production platform. This section reveals two depressions of high-diffractivity to a depth of $180 \mathrm{~m}$ (outlined by the dashed white line). The lower boundary of the anomaly is highly curved. The equivalent conventional seismic image (Figure 11) indicates lateral bedding, which suggests that the curved nature of the boundary is not related to geologic structure. The high diffractivity may not be explained by intensive faulting as well - the similarity attribute indicates no anomalies consistent with this high-diffractivity area (Figure 12).

To evaluate lateral extension of the high-diffractivity zones, we extracted a horizon slice from the diffraction energy volume (Figure 14a). One may notice two zones (indicated by dashed outlines) which reveal increased diffractivity. One zone is extended in the vicinity of the platform, another zone is located in the west (right) portion of the P-Cable survey. In the area of study, we assume subtle lateral changes in lithologic composition and explain the presence of the high-diffractivity anomalies by fluid saturation. An important detail is that the interval of the high-diffractivity anomalies are characterized by high electrical resistivity (Figures 7 and 10), which allows the possibility for the presence of hydrocarbon migrated from the underlying strata. This assumption can be advocated by spectral decomposition (CWT analysis with the Mortlet wavelet was performed in the depth domain). The low-frequency component (Figure 13a) discloses an anomaly just below the high-diffractivity area. We interpret this feature as a low-frequency shadow (Chopra and Marfurt, 2007) characteristic for gas-saturated intervals.

Diffraction energy correlates well with the similarity attribute at the faults indicated by the yellow arrows in Figure 14b. However, two interpreted fluid-saturated areas are not 
evident in the similarity slice. This example illustrates two different sources of diffracted waves, which are faults and fluid saturated small fracture or pore networks. The faults have specific structural signatures such as vertical offsets that makes them easily detectable for seismic attributes operating on conventional seismic images. Conversely, diffraction waves generated by smaller scale fractures and pores networks are much weaker and are often difficult to distinguish from noise level. The latter diffractions are the primary target for diffraction imaging.

Below a depth of 240-275 m, diffraction energy decreases further (Figure 15). A few subtle elongated clusters, which are associated with faults, can be detected in diffraction energy depth slices (Figure 16). Another perceptible feature is an acquisition footprint that becomes more prominent at those depths (shown by red arrows). A fault is a strong scatterer that generates diffractions dominating a diffraction image. The fact that energy from the strongest diffractors is comparable with noise level implies an unacceptably low signal-to-noise ratio and the inadvisability of diffraction analysis in intervals below $275 \mathrm{~m}$. Note that for conventional seismic surveys, which operate with much more powerful sources and are optimized for investigating a much deeper geologic section, the diffraction analysis zone should be much deeper.

\section{CONCLUSIONS}

To evaluate the ability for seal intervals to retain fluids in underlying reservoirs, we performed diffraction analysis of the shallow intervals (above $200 \mathrm{~m}$ ) imaged by high-resolution P-Cable seismic data. We isolated diffractions from the P-Cable data and analyzed diffraction strength across the section, and observed both narrow-linear and broad-sinuous zones of high diffractivity. We interpreted these broad regions to be a response to variable fluid composition saturation including hydrocarbons, which may have escaped from underlying reservoirs. These migrating fluids reach the near subsurface, fill the pore space, thus changing the acoustic 
impedance enough to generate detectable diffraction waves.

We observed that diffraction energy was not distributed evenly vertically or horizontally. Several vertical intervals with variable diffraction strength were recognized. The strongest diffractions were located in the upper part of the analyzed section (50-100 m), in which multiple depositional channels were inferred. These strong diffractors were concentrated along depth intervals characterized by reduced electrical resistivity in nearby wireline well logs that allowed associating them with brine. In the underlying intervals, diffraction energy was significantly lower and revealed uneven lateral distribution. Two high-diffractivity anomalies extending vertically and laterally were examined. We assumed the high-diffractivity anomalies to be hydrocarbons that have migrated from underlying reservoirs because of 1) laterally extensive sub-horizontal strata and inferred lateral continuity of lithologic properties in conjunction with 2) high electrical resistivity of correlative the strata in wireline well logs of nearby wells and 3) the associated seismic low-frequency shadow. In addition, we observed a large number of faults and accompanying subseismic throws (or, possibly, fracture corridors) that could serve as path-ways for fluid migration. All these features suggested poor sealing capacity of the underlying cap rocks.

Our work introduced diffraction imaging applications for high-resolution 3D P-Cable seismic data. Because of P-Cable acquisition geometries, we were able to get high-resolution (bin size of $6.25 \mathrm{~m}$ ) seismic imaging of the strata. In the diffraction image obtained, we interpreted depositional channels, faults and subvertical fracture network. We consider the diffraction signals to be reliable between the depths of 50 to $275 \mathrm{~m}$. 
In addition, we tested diffraction focusing analysis for velocity model building. We were able to compile a velocity profile, subsequently used for the P-Cable data migration. Satisfactory focusing of the vertical scatterers, which were interpreted as subseismic throws, validated the velocity model used. The diffraction focusing option appears quite valuable for P-Cable data processing because of short offset and limitations of the standard velocity analysis.

\section{ACKNOWLEDGMENTS}

The P-Cable data were processed by Thomas Hess. The wireline well logs were digitized under supervision of Iulia Olariu. We thank Caroline Breton for assistance with the graphics and Mark Shuster for many fruitful discussions. This material is based upon work supported by the Department of Energy under DOE Award Number DE-FE0026083. P-Cable seismic data were acquired with support from the Department of Energy under DOE Award Number DE-FE0001941. Publication authorized by the Director, Bureau of Economic Geology. 


\section{REFERENCES}

Ahr, W., 2008, Geology of carbonate reservoirs: the identification, description, and characterization of hydrocarbon reservoirs in carbonate rocks: John Wiley \& Sons, Inc., Hoboken, New Jersey, $277 p$.

Antonellini, M., and A. Aydin, 1994, Effect of faulting on fluid flow in porous sandstones: Petrophysical properties: AAPG Bulletin, 78, 355-377.

Benfield, N., A. Guise, and D. Chase, 2016, Diffraction imaging - a tool to reduce exploration and development risk: First Break, 34, 57-63.

Bradshaw, B., and J. Watkins, 1994, Growth-fault evolution in offshore Texas: Transactions: Gulf Coast Association of Geological Societies, 44, 103-110.

Brookshire, B., F. Landers, and J. Stein, 2015, Applicability of ultra-high-resolution 3D seismic data for geohazard identification at mid-slope depths in the Gulf of Mexico: Initial results: Underwater Technology, 32, 271-278.

Chopra, S., and K. Marfurt, 2007, Seismic attributes for prospect identification and reservoir characterization: Society of Exploration Geophysicists and European Association of Geoscientists and Engineers, $464 \mathrm{p}$.

de Rooij, M., and K. Tingdahl, 2002, Meta-attributes - the key to multivolume, multiattribute interpretation: The Leading Edge, 21, 1050-1053.

Edlmann, K., A. Niemi, J. Bensabat, R. Haszeldine, and C. McDermott, 2016, Mineralogical properties of the caprock and reservoir sandstone of the Heletz field scale experimental $\mathrm{CO}_{2}$ injection site, Israel; and their initial sensitivity to $\mathrm{CO}_{2}$ injection: International Journal of Greenhouse Gas Control, 48, 94-104.

Fomel, S., E. Landa, and M. T. Taner, 2007, Poststack velocity analysis by separation and imaging of seismic diffractions: Geophysics, 72, U89-U94. 
Galloway, W., 1989, Genetic stratigraphic sequences in basin analysis II: Application to Northwest Gulf of Mexico Cenozoic Basin: AAPG Bulletin, 73, 143-154.

Hubbert, K., 1953, Entrapment of petroleum under hydrodynamic conditions: AAPG Bulletin, 37, 1954-2026.

Klokov, A., and S. Fomel, 2012, Separation and imaging of seismic diffractions using migrated dip-angle gathers: Geophysics, 77, S131-S143.

Klokov, A., D. Irkabaev, O. C. Ogiesoba, and N. Munasypov, 2015, Correlation between seismic diffractions extracted from vertical seismic profiling data and borehole logging in a carbonate environment: Interpretation, 3, T121-T129.

Kluesner, J. W., and D. S. Brothers, 2016, Seismic attribute detection of faults and fluid pathways within an active strike-slip shear zone: New insights from high-resolution 3D P-Cable seismic data along the Hosgri Fault, offshore California: Interpretation, 4, SB131SB148.

Landa, E., 2013, Role of wave field diffraction component in seismic imaging: Seismic Technology, 10, 1-48.

Lippus, C., 2014, High-resolution revolution: OilField Technology, 7, 57-62.

McDonnell, A., M. Hudec, and M. Jackson, 2009, Distinguishing salt welds from shale detachments on the inner Texas shelf, western Gulf of Mexico: Basin Research, 21, 47-59.

Meckel, T. A., and F. J. Mulcahy, 2016, Use of novel high-resolution 3D marine seismic technology to evaluate Quaternary fluvial valley development and geologic controls on shallow gas distribution, inner shelf, Gulf of Mexico: Interpretation, 4, SC35-SC49.

Ogiesoba, O. C., A. Klokov, and R. Hernandez, 2015, Diffraction imaging of polygonal faults within a submarine volcanic terrain, maverick basin, south texas: Interpretation, 


\section{3, SF81-SF99.}

Petersen, C. J., S. B"unz, S. Hustoft, J. Mienert, and D. Klaeschen, 2010, High-resolution P-Cable 3D seismic imaging of gas chimney structures in gas hydrated sediments of an Arctic sediment drift: Marine and Petroleum Geology, 27, 1981-1994.

Plaza-Faverola, A., S. B"unz, and J. Mienert, 2011, Repeated fluid expulsion through sub-seabed chimneys offshore Norway in response to glacial cycles: Earth and Planetary Science Letters, 305, 297-308.

Sava, P. C., B. Biondi, and J. Etgen, 2005, Wave-equation migration velocity analysis by focusing diffractions and reflections: Geophysics, 70, U19-U27.

Schowalter, T., 1979, Mechanics of secondary hydrocarbon migration and entrapment: AAPG Bulletin, 63, 723-760.

Seni, S.J., Hentz, T.F., Kaiser, W.R. \& Wermund, E.G. Jr. (1997) Atlas of Northern Gulf of Mexico Gas and Oil Reservoirs, Volume 1: Miocene and Older Reservoirs, Plate 3: Structure of Northern Gulf of Mexico. The University of Texas at Austin, Bureau of Economic Geology, 199pp. Austin, Texas.

Singhroha, S., S. Bünz, A. Plaza-Faverola, and S. Chand, 2016, Gas hydrate and free gas detection using seismic quality factor estimates from high-resolution P-cable 3D seismic data: Interpretation, 4, SA39-SA54.

Smith, D., 1966, Theoretical considerations of sealing and non-sealing faults: AAPG Bulletin, $50,363-374$.

Sturzu, I., A. Popovici, M. Pelissier, J. Wolak, and T. Moser, 2014, Diffraction imaging of the Eagle Ford shale: First Break, 32, 49-60.

Zhu, J., L. Lines, and S. Gray, 1998, Smiles and frowns in migration/velocity analysis: Geophysics, 63, 1200-1209. 


\section{LIST OF FIGURES}

1 Map of the Texas Coastal Bend and Texas State Waters showing P-Cable survey location. Clemente-Tomas Fault outline is from Seni et al. (1997); fault located where it offsets the top of the Miocene geologic section.

2 Velocity profile obtained by diffraction focusing analysis. This velocity model was used for

P-Cable seismic imaging.

3 Velocity model optimization using diffraction focusing analysis. (a) Diffraction image (inline 112) obtained after migration with constant velocity, (b) the same section after migration with the optimized velocity. Two zoom panels in the right side of the images illustrate better focusing of diffractors achieved by using the optimized model.

4 Inline 112 showing (a) the diffraction energy attribute and (b) the conventional seismic image. The sections are overlaid by borehole logs: spontaneous potential log (left, dark colors indicate more shale content) and electrical resistivity log (right). White arrows indicate two high-diffractivity intervals, which correlate with electrical resistivity decrease. Green arrows show faults connecting those two intervals. The shadow area at crossline 1800 (i.e. no data) is caused by a production platform.

5 (a) Diffraction energy attribute and (b) the conventional seismic image extracted along the horizon H1. Red dashed lines indicate faults that connect two intervals of high diffractivity associated with brine saturation. Yellow arrows show fluvial channels, which are characterized by strong diffraction power. Red dot locates a well in which the wireline logs were recorded.

6 Diffraction energy attribute extracted along three fault planes interpreted in Figures 4 and 5. Higher diffraction energy power locates zones with higher permeability characteristics. Dashed black line indicates a position of inline 112 . The low diffractivity zone indicated by the red double arrow is probably caused by low signal power in this area, not perfect sealing features. 
7 Inline 150 showing (a) the diffraction energy attribute and (b) the diffraction image. The shadow area at crossline 1500 is caused by a production platform. The sections are overlain by borehole logs projected from the actual position: spontaneous potential log (left, dark colors indicate higher shale content) and electrical resistivity log (right). Red arrows indicate faults, green arrows indicate more subtle diffractors which were interpreted as subseismic throws (or, possibly, fracture corridors).

8 Inline 150 showing the conventional seismic image. The shadow area at crossline 1500 is caused by a production platform. The sections are overlain by borehole logs projected from the actual position: spontaneous potential log (left, dark colors indicate higher shale content) and electrical resistivity log (right). Red arrows indicate faults, green arrows indicate more subtle diffractors which were interpreted as subseismic throws (or, possibly, fracture corridors).

9 Inline 150 showing (a) the similarity attribute and (b) fracture density attribute. The shadow area at crossline 1500 is caused by a production platform. The sections are overlain by borehole logs projected from the actual position: spontaneous potential log (left, dark colors indicate higher shale content) and electrical resistivity log (right). Red arrows indicate faults, green arrows indicate more subtle diffractors which were interpreted as subseismic throws (or, possibly, fracture corridors).

10 Inline 300 showing the diffraction energy attribute. The sections are overlaid by borehole logs projected from the actual position: spontaneous potential log (left, dark colors indicate more shale content) and electrical resistivity log (right). White dashed line denotes the boundary between the upper high-diffractivity area and the underlying low-diffractivity area. 
11 Inline 300 showing the conventional seismic image. The sections are overlaid by borehole logs projected from the actual position: spontaneous potential log (left, dark colors indicate more shale content) and electrical resistivity log (right). White dashed line denotes the boundary between the upper high-diffractivity area and the underlying low-diffractivity area.

12 Inline 300 showing the similarity attribute. The sections are overlaid by borehole logs projected from the actual position: spontaneous potential log (left, dark colors indicate more shale content) and electrical resistivity log (right). White dashed line denotes the boundary between the upper high-diffractivity area and the underlying low-diffractivity area.

13 Inline 300 showing frequency decomposition results: (a) 66 cycles/km component and (b) 200 cycles/km component. The sections are overlaid by borehole logs projected from the actual position: spontaneous potential log (left, dark colors indicate more shale content) and electrical resistivity log (right). White dashed line denotes the boundary between the upper high-diffractivity area and the underlying low-diffractivity area.

14 (a) Diffraction energy attribute and (b) similarity attribute extracted along horizon $\mathrm{H} 2$. Dashed lines denote the boundary between the high-diffractivity and low-diffractivity zones. Yellow arrows indicate faults on which two attributes correlate well. Red dot locates a well in which the wireline logs were recorded. Dotted line locates the inline section in Figures 10-13.

15 Inline 300 showing the diffraction energy attribute. The sections are overlaid by borehole logs projected from the actual position: spontaneous potential log (left, dark colors indicate more shale content) and electrical resistivity log (right). Dashed white outline denotes the boundary between upper high-diffractivity area and underlying low-diffractivity area. 
16 Depth slice from $300 \mathrm{~m}$ for diffraction energy attribute. Yellow arrows indicate subtle linear clusters associated with faults. Red arrows indicate acquisition footprint which appears prominent at that depth. Red dot locates a well in which the wireline logs were recorded. Figure 2: Velocity profile obtained by diffraction focusing analysis. This velocity model was used for P-Cable seismic imaging. 


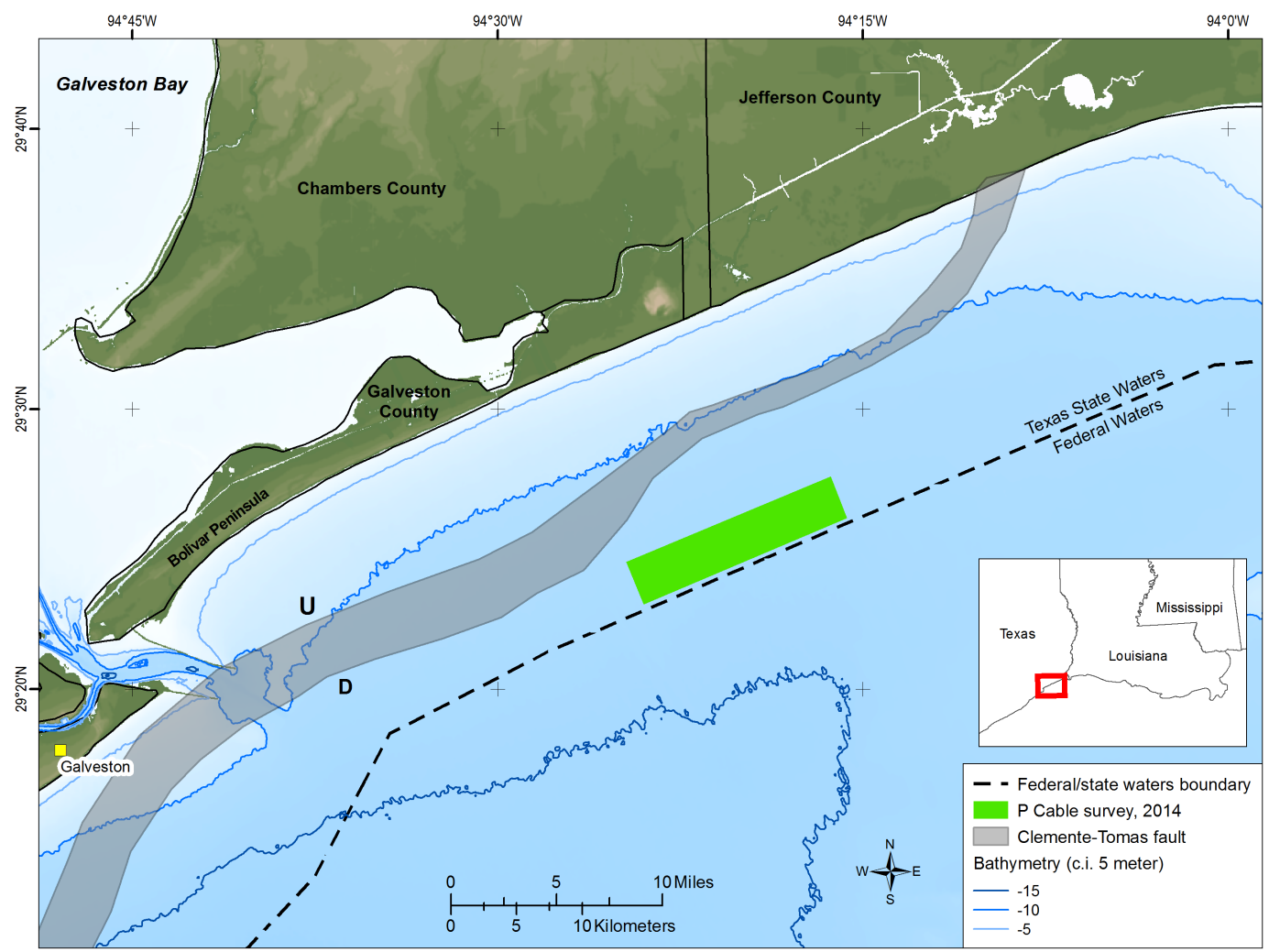

Figure 1: Map of the Texas Coastal Bend and Texas State Waters showing P-Cable survey location. Clemente-Tomas Fault outline is from Seni et al. (1997); fault located where it offsets the top of the Miocene geologic section.

Klokov et al. 


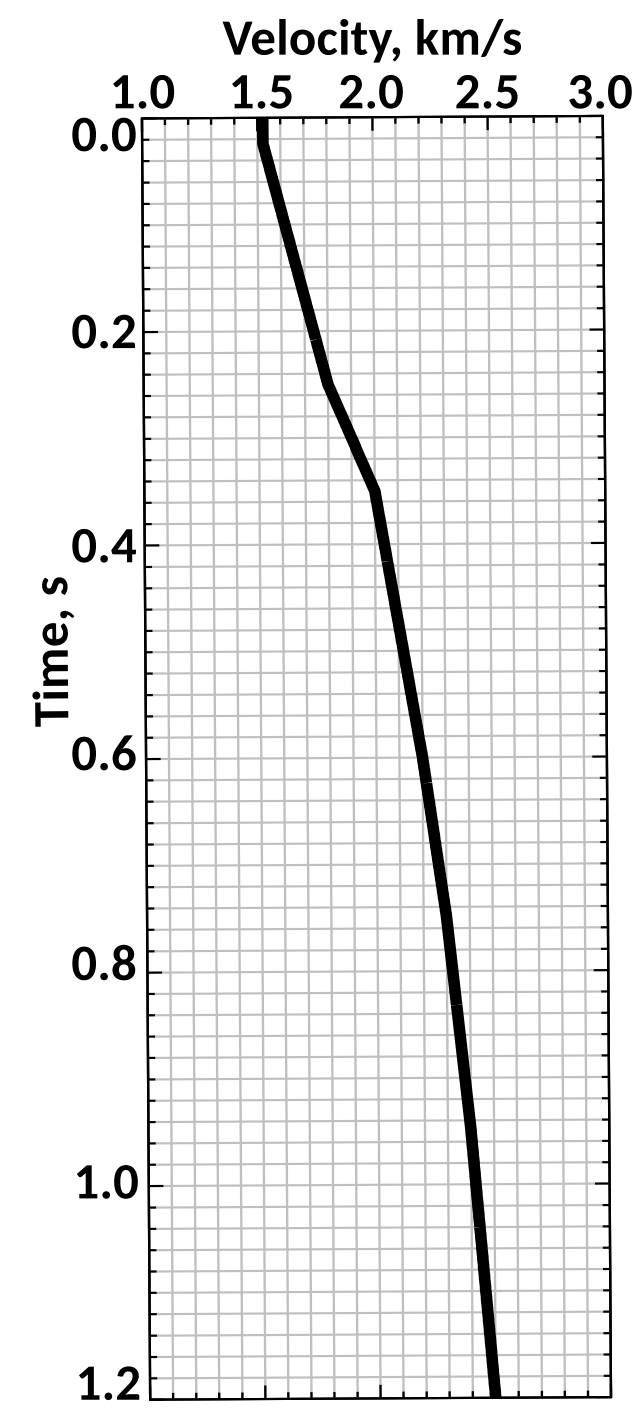

Figure 2: Velocity profile obtained by diffraction focusing analysis. This velocity model was used for P-Cable seismic imaging.

Klokov et al. 


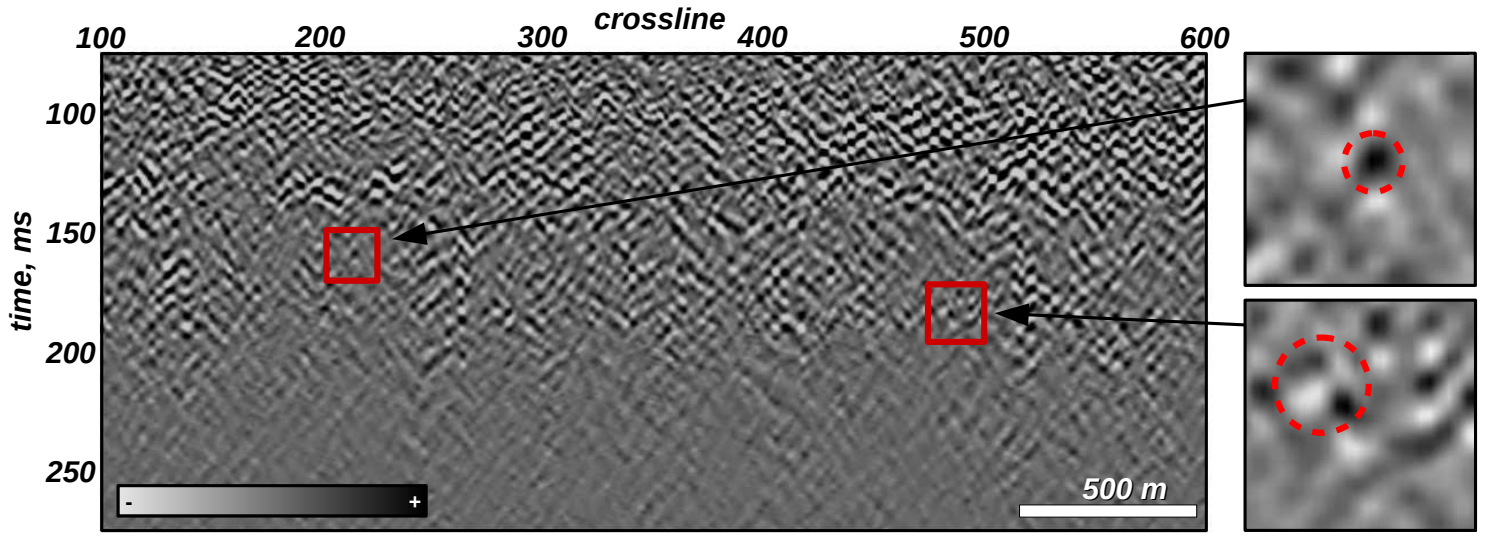

a

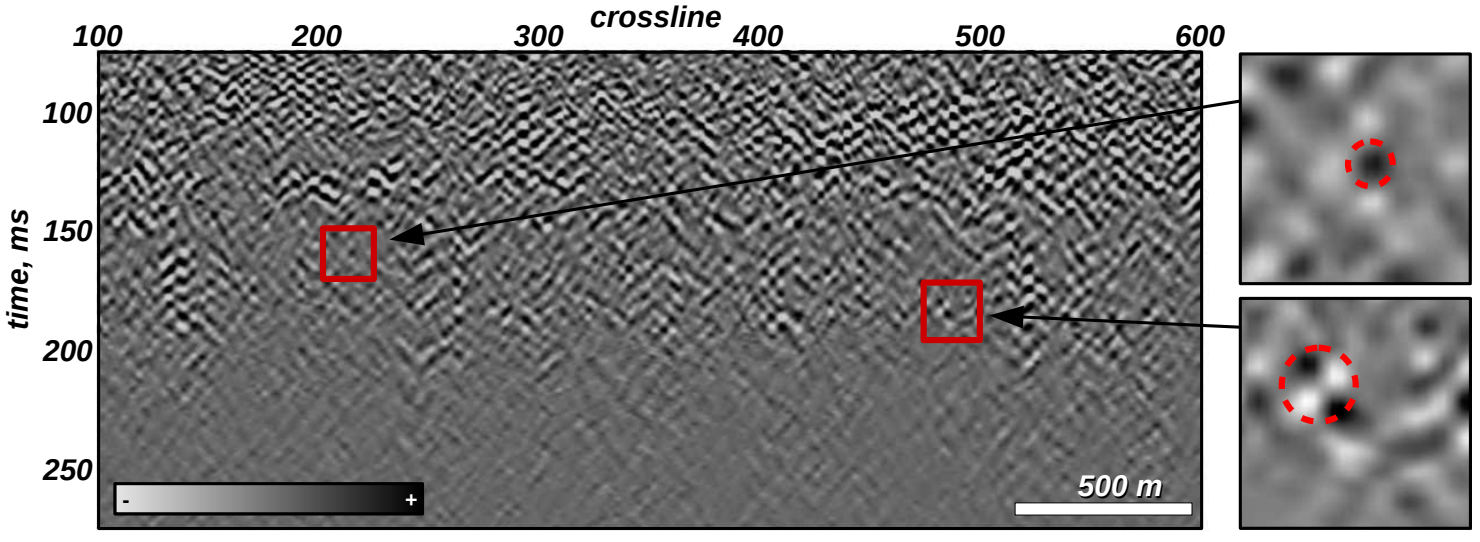

$\mathrm{b}$

Figure 3: Velocity model optimization using diffraction focusing analysis. (a) Diffraction image (inline 112) obtained after migration with constant velocity, (b) the same section after migration with the optimized velocity. Two zoom panels in the right side of the images illustrate better focusing of diffractors achieved by using the optimized model.

Klokov et al. - 

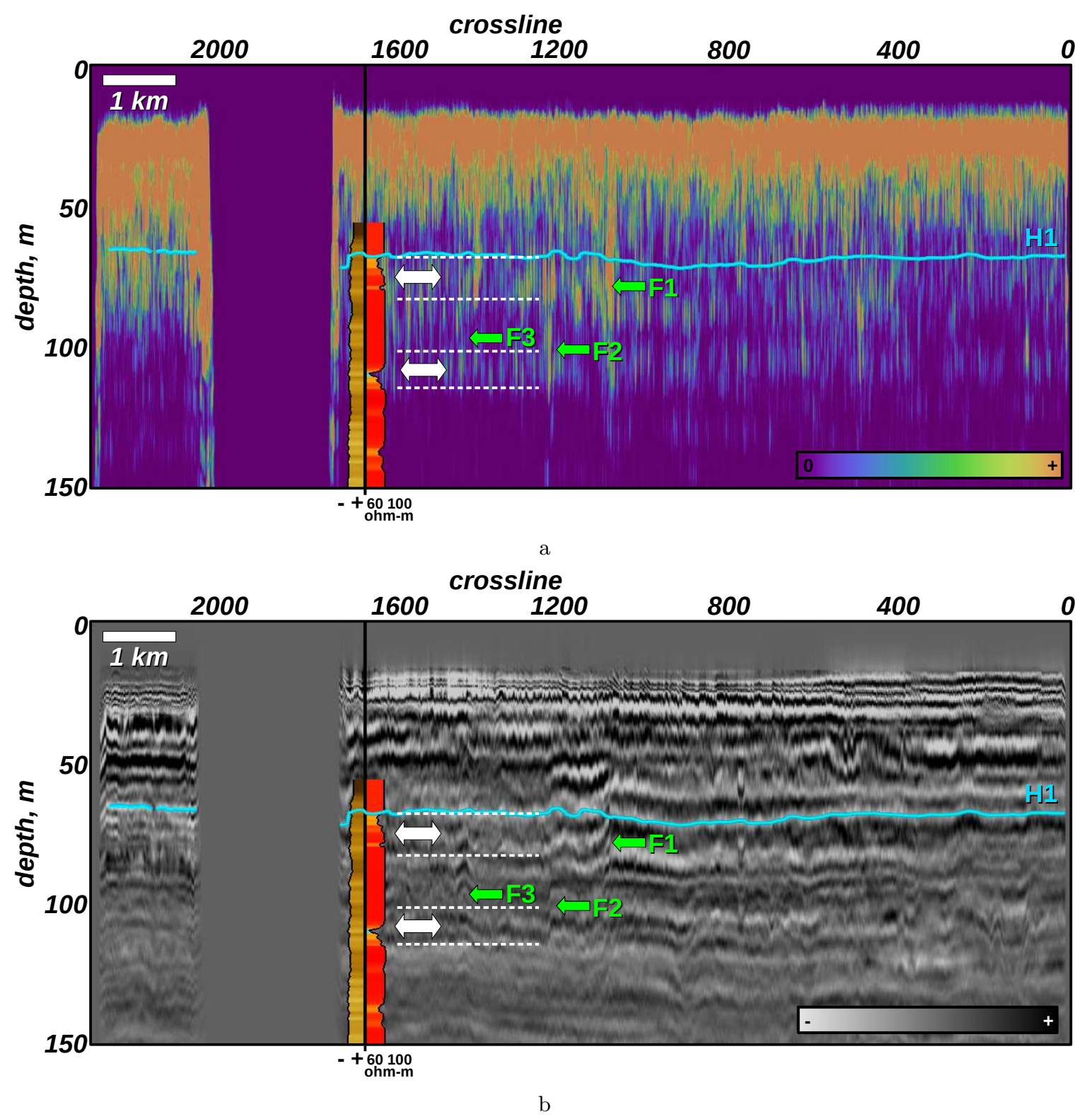

Figure 4: Inline 112 showing (a) the diffraction energy attribute and (b) the conventional seismic image. The sections are overlaid by borehole logs: spontaneous potential log (left, dark colors indicate more shale content) and electrical resistivity log (right). White arrows indicate two high-diffractivity intervals, which correlate with electrical resistivity decrease. Green arrows show faults connecting those two intervals. The shadow area at crossline 1800 (i.e. no data) is caused by a production platform.

Klokov et al. - 

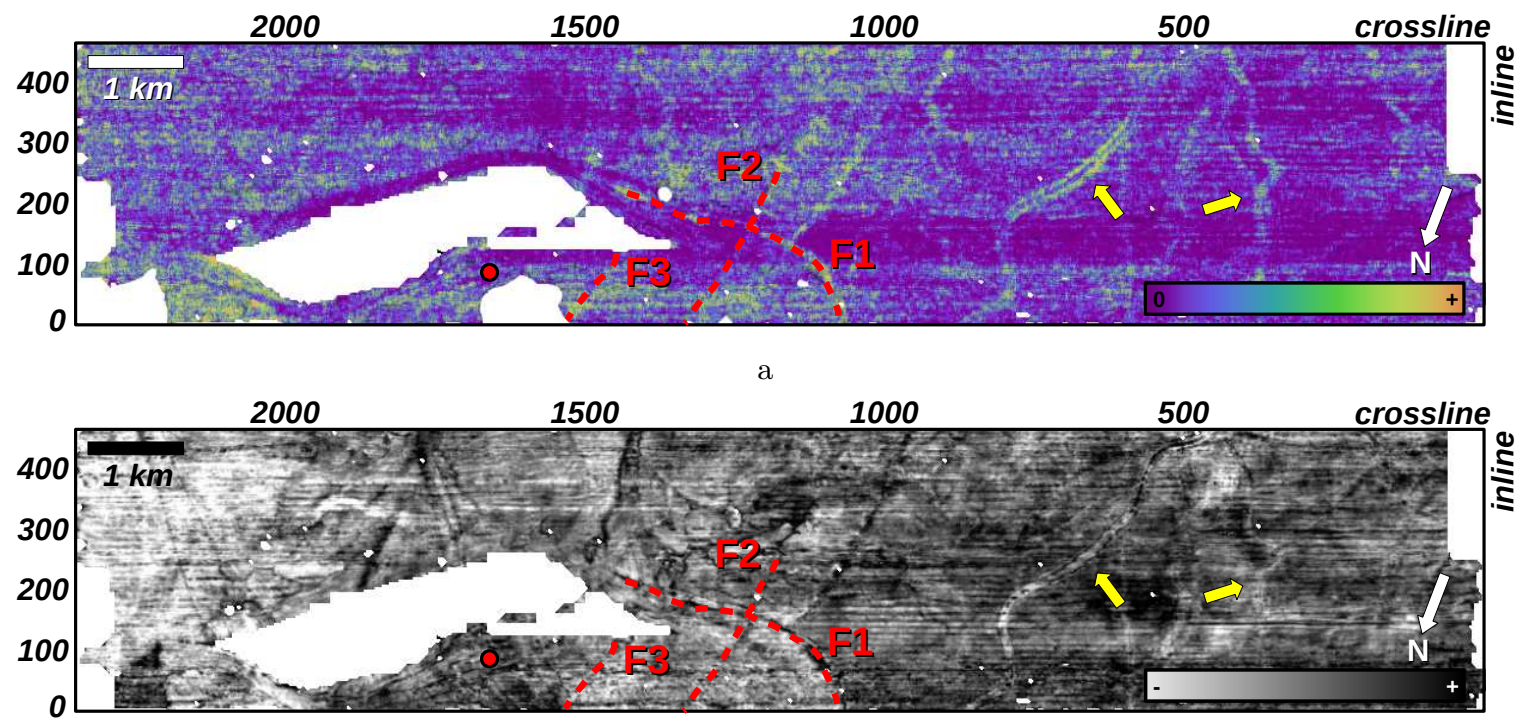

$\mathrm{b}$

Figure 5: (a) Diffraction energy attribute and (b) the conventional seismic image extracted along the horizon H1. Red dashed lines indicate faults that connect two intervals of high diffractivity associated with brine saturation. Yellow arrows show fluvial channels, which are characterized by strong diffraction power. Red dot locates a well in which the wireline logs were recorded.

Klokov et al. 

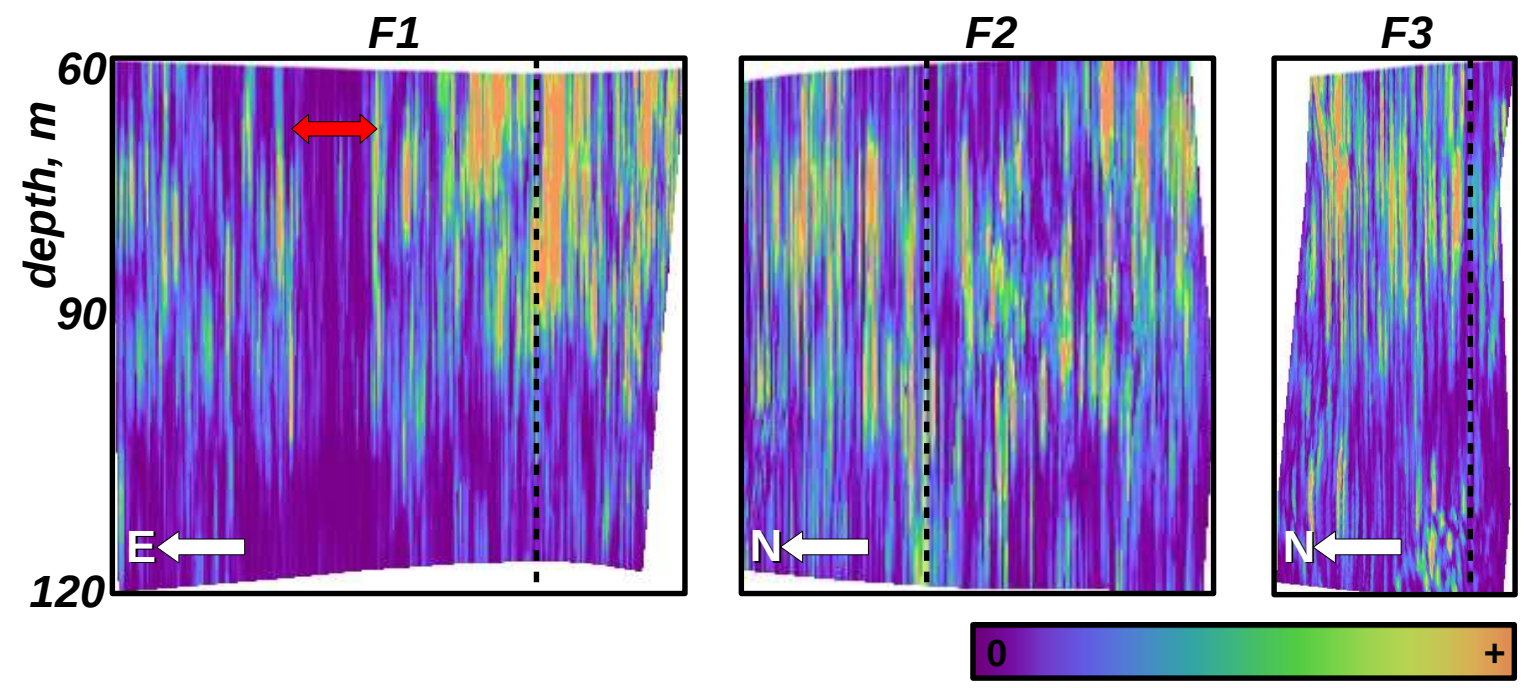

Figure 6: Diffraction energy attribute extracted along three fault planes interpreted in Figures 4 and 5. Higher diffraction energy power locates zones with higher permeability characteristics. Dashed black line indicates a position of inline 112. The low diffractivity zone indicated by the red double arrow is probably caused by low signal power in this area, not perfect sealing features.

Klokov et al. - 

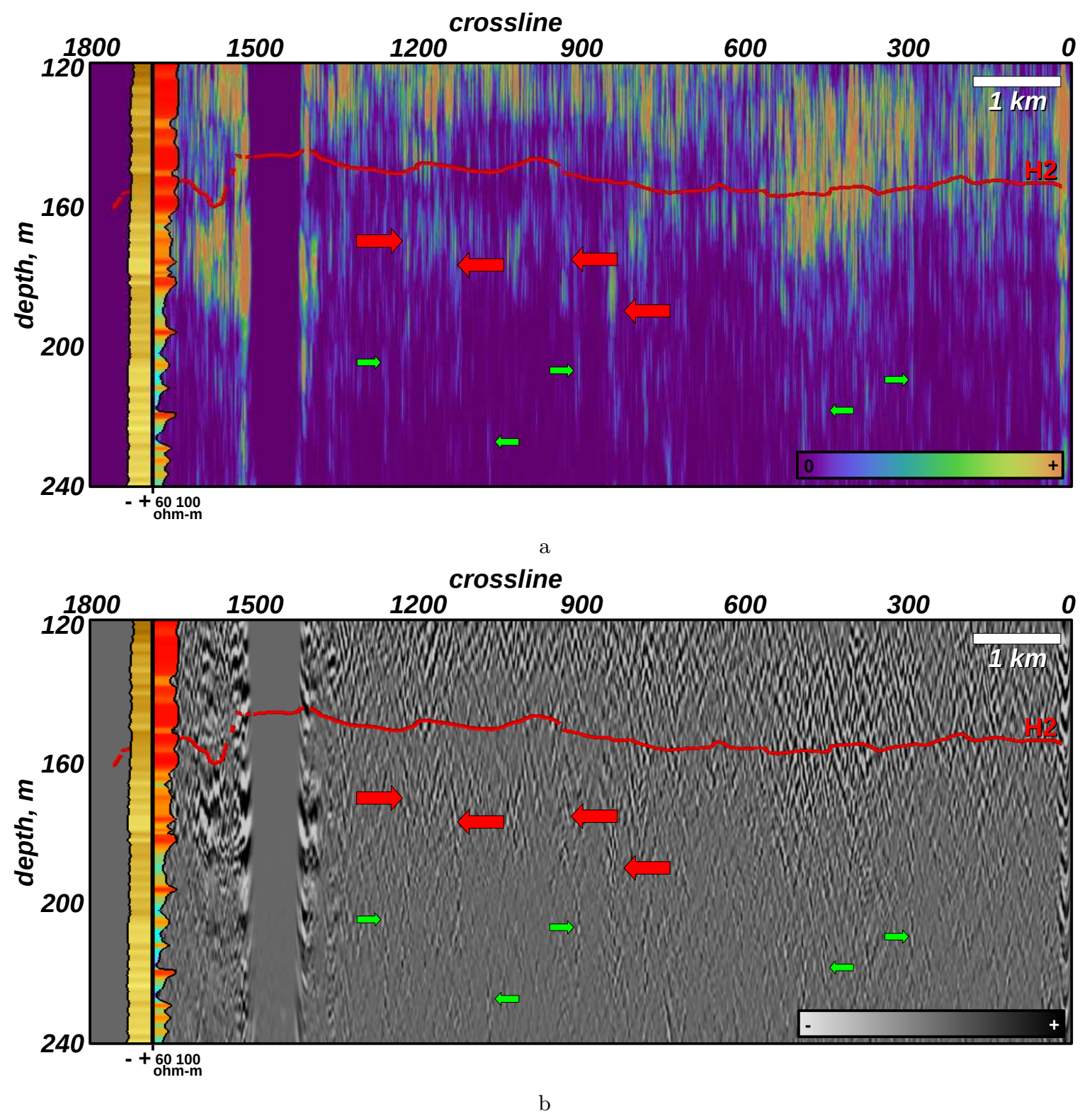

Figure 7: Inline 150 showing (a) the diffraction energy attribute and (b) the diffraction image. The shadow area at crossline 1500 is caused by a production platform. The sections are overlain by borehole logs projected from the actual position: spontaneous potential log (left, dark colors indicate higher shale content) and electrical resistivity log (right). Red arrows indicate faults, green arrows indicate more subtle diffractors which were interpreted as subseismic throws (or, possibly, fracture corridors).

Klokov et al. - 


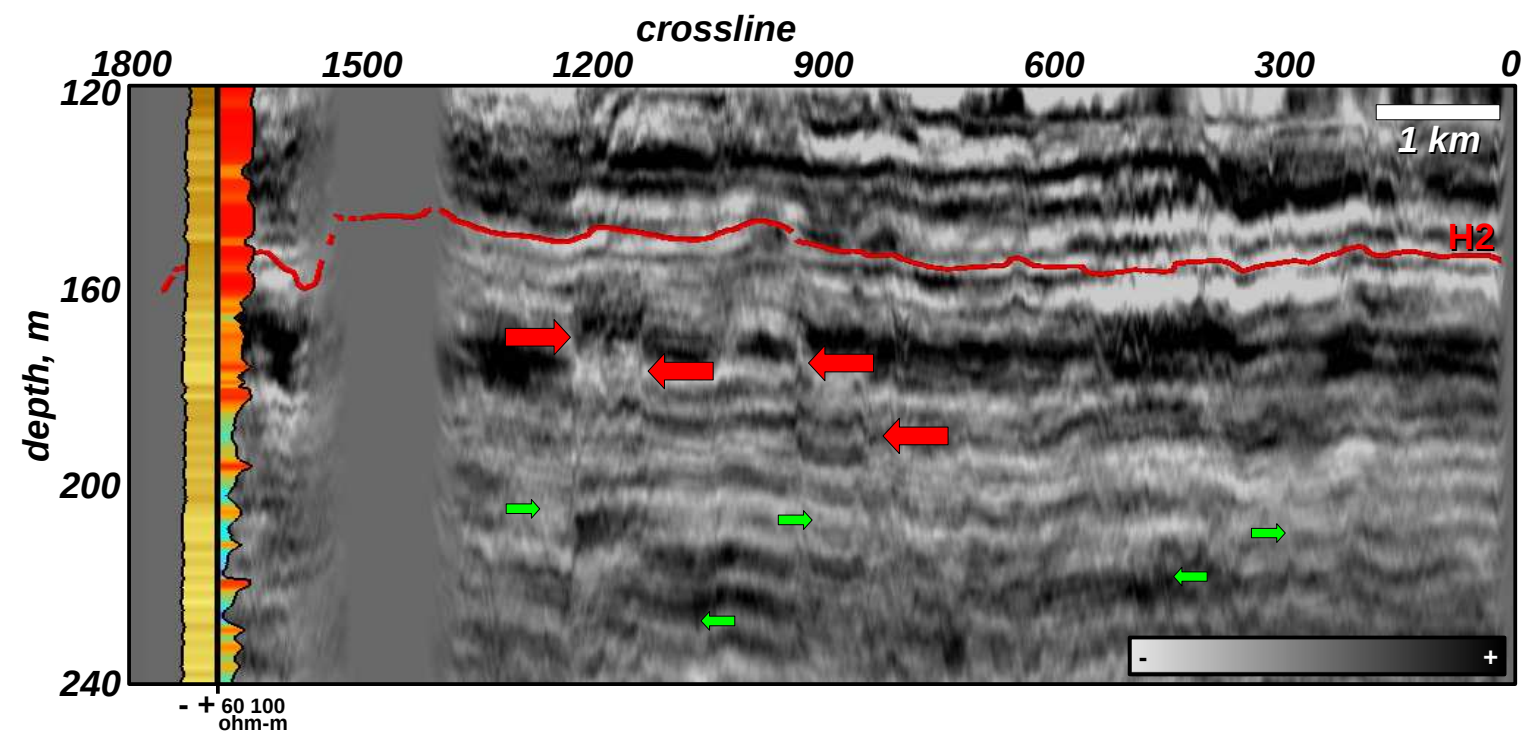

Figure 8: Inline 150 showing the conventional seismic image. The shadow area at crossline 1500 is caused by a production platform. The sections are overlain by borehole logs projected from the actual position: spontaneous potential log (left, dark colors indicate higher shale content) and electrical resistivity log (right). Red arrows indicate faults, green arrows indicate more subtle diffractors which were interpreted as subseismic throws (or, possibly, fracture corridors).

Klokov et al. 

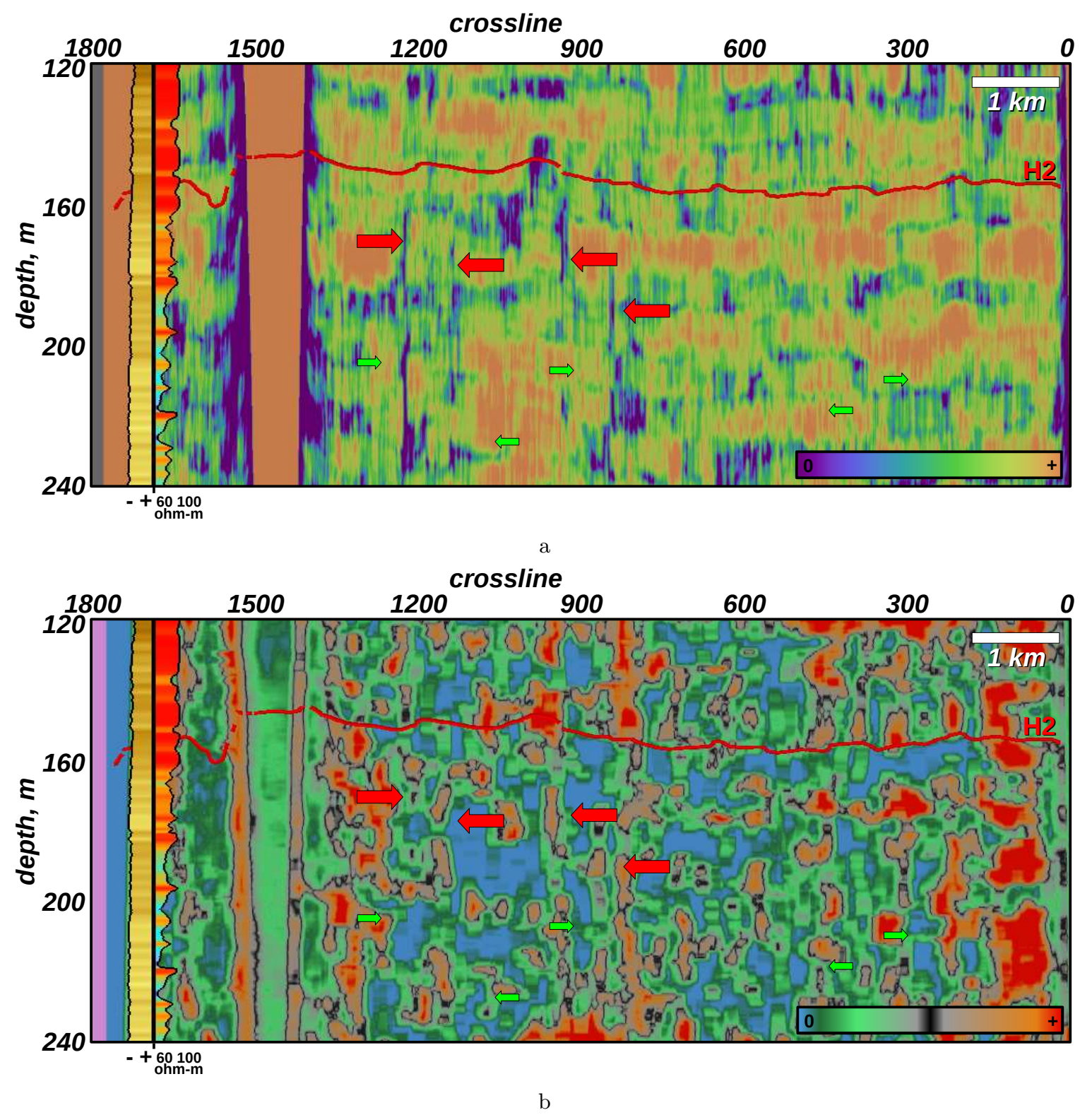

Figure 9: Inline 150 showing (a) the similarity attribute and (b) fracture density attribute. The shadow area at crossline 1500 is caused by a production platform. The sections are overlain by borehole logs projected from the actual position: spontaneous potential log (left, dark colors indicate higher shale content) and electrical resistivity log (right). Red arrows indicate faults, green arrows indicate more subtle diffractors which were interpreted as subseismic throws (or, possibly, fracture corridors).

Klokov et al. - 


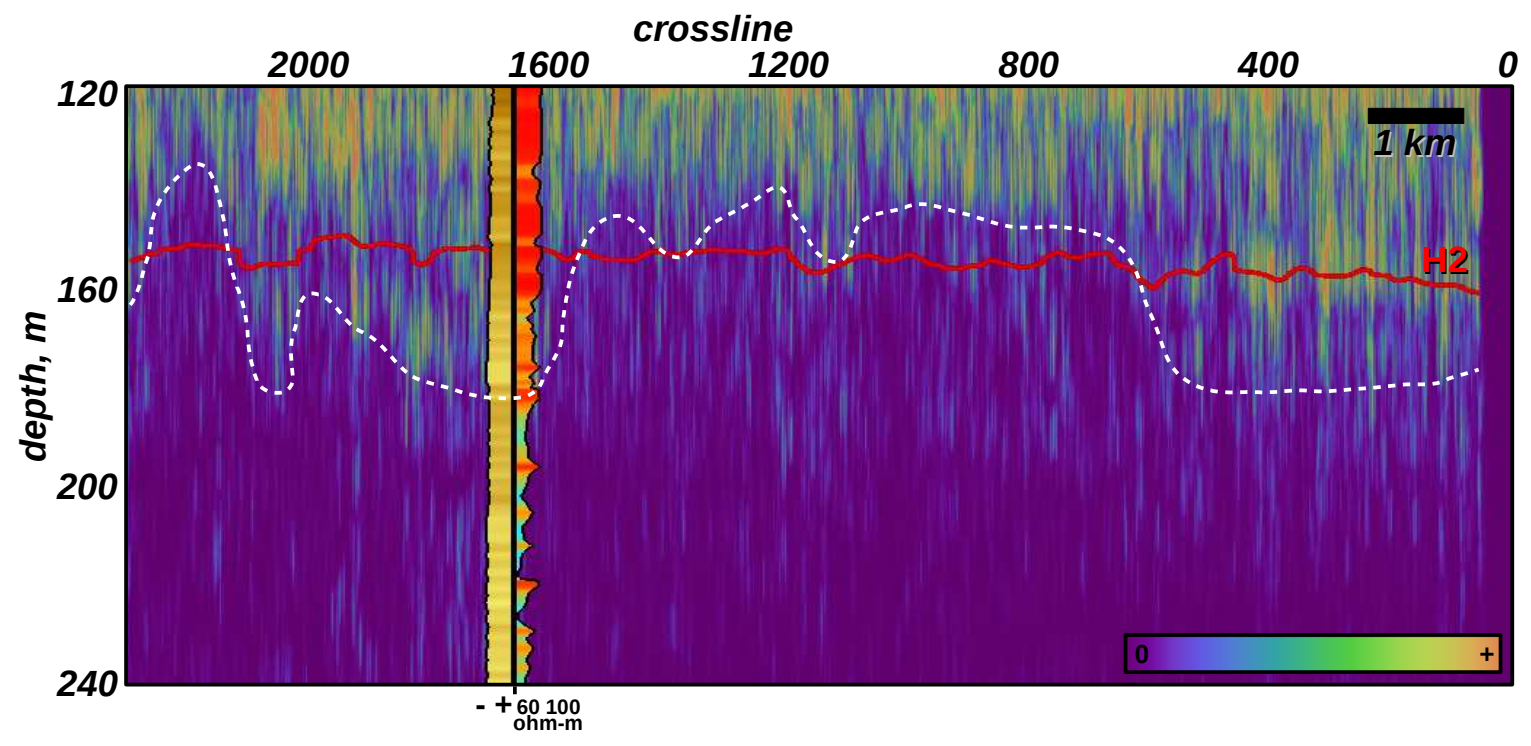

Figure 10: Inline 300 showing the diffraction energy attribute. The sections are overlaid by borehole logs projected from the actual position: spontaneous potential log (left, dark colors indicate more shale content) and electrical resistivity log (right). White dashed line denotes the boundary between the upper high-diffractivity area and the underlying low-diffractivity area.

Klokov et al. 


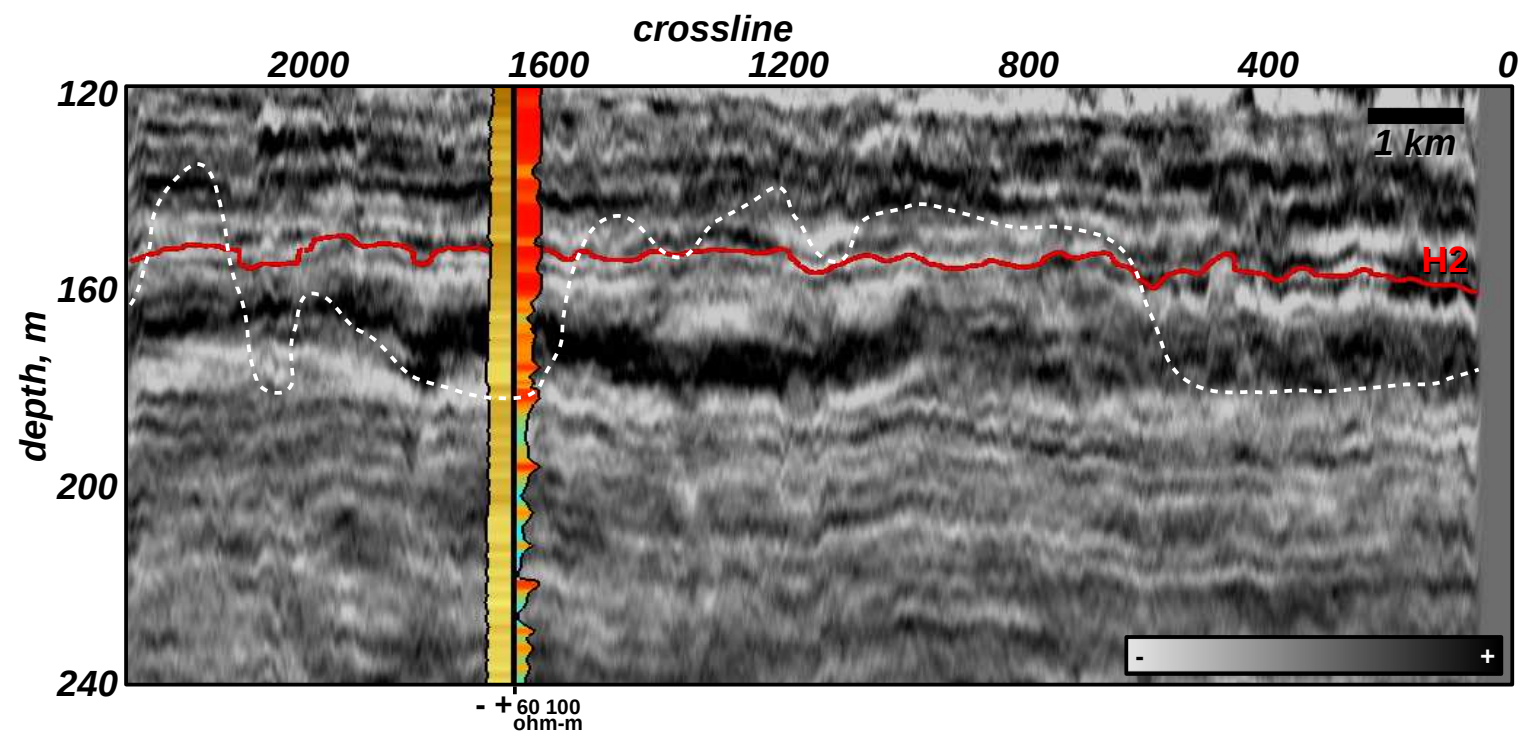

Figure 11: Inline 300 showing the conventional seismic image. The sections are overlaid by borehole logs projected from the actual position: spontaneous potential log (left, dark colors indicate more shale content) and electrical resistivity log (right). White dashed line denotes the boundary between the upper high-diffractivity area and the underlying low-diffractivity area.

Klokov et al. - 


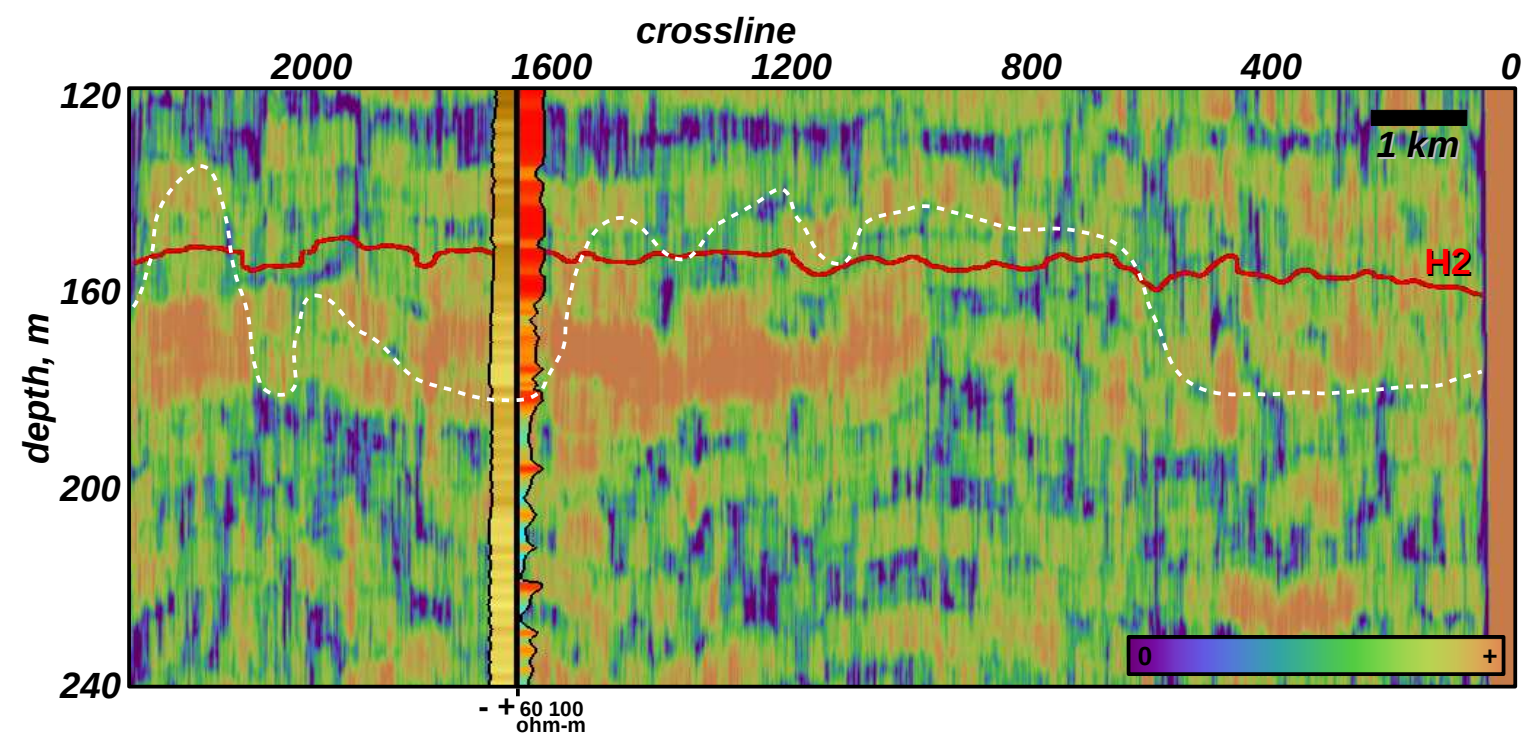

Figure 12: Inline 300 showing the similarity attribute. The sections are overlaid by borehole logs projected from the actual position: spontaneous potential log (left, dark colors indicate more shale content) and electrical resistivity log (right). White dashed line denotes the boundary between the upper high-diffractivity area and the underlying low-diffractivity area.

Klokov et al. 

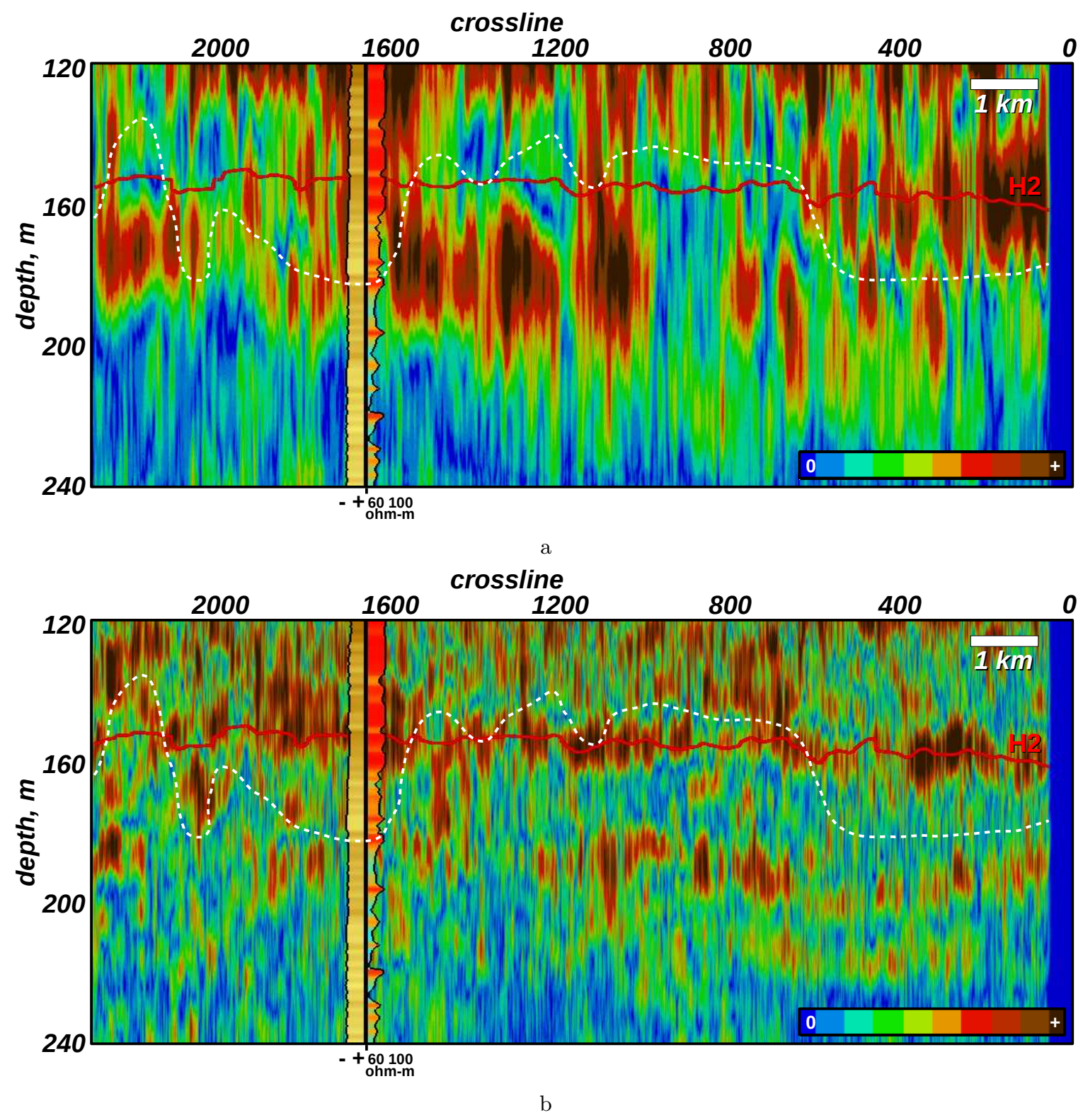

Figure 13: Inline 300 showing frequency decomposition results: (a) 66 cycles/km component and (b) 200 cycles $/ \mathrm{km}$ component. The sections are overlaid by borehole logs projected from the actual position: spontaneous potential log (left, dark colors indicate more shale content) and electrical resistivity log (right). White dashed line denotes the boundary between the upper high-diffractivity area and the underlying low-diffractivity area.

Klokov et al. - 


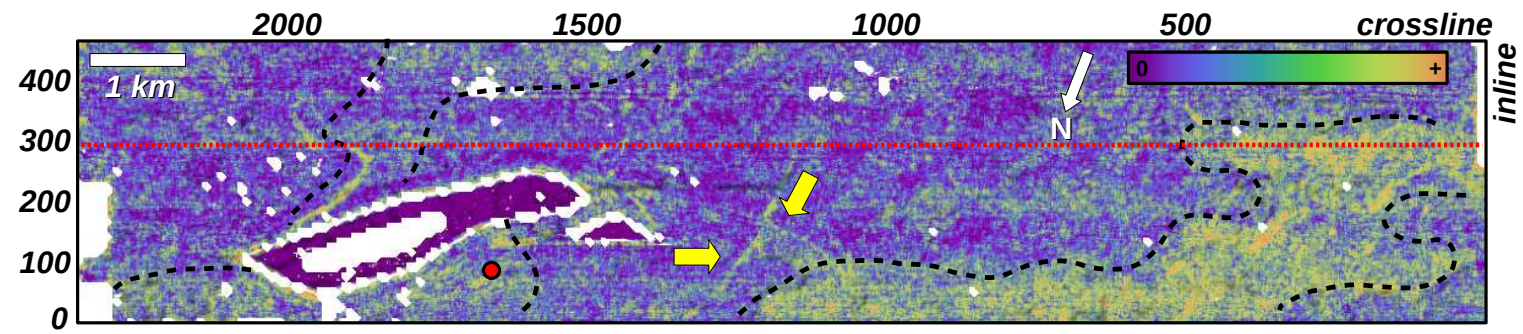

$\mathrm{a}$

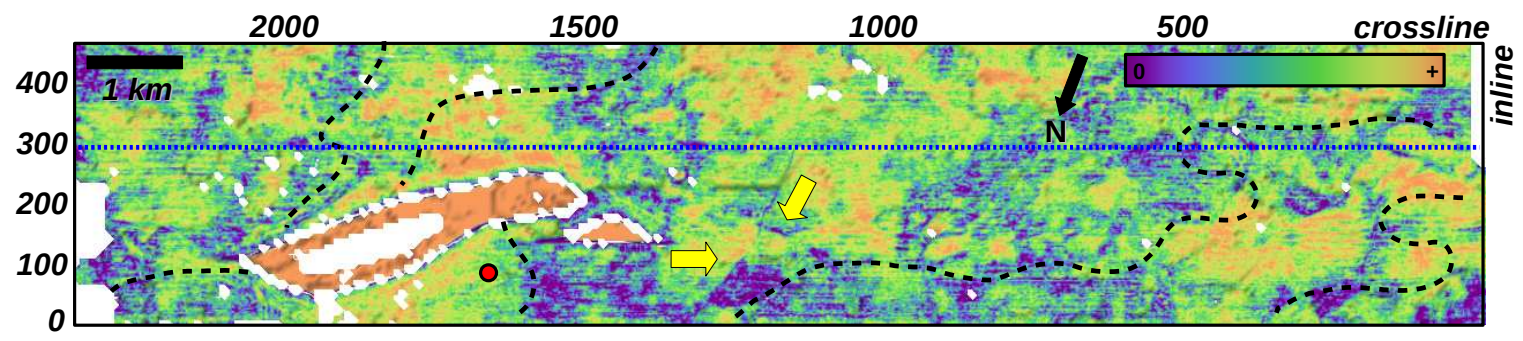

$\mathrm{b}$

Figure 14: (a) Diffraction energy attribute and (b) similarity attribute extracted along horizon H2. Dashed lines denote the boundary between the high-diffractivity and lowdiffractivity zones. Yellow arrows indicate faults on which two attributes correlate well. Red dot locates a well in which the wireline logs were recorded. Dotted line locates the inline section in Figures 10-13.

Klokov et al. 


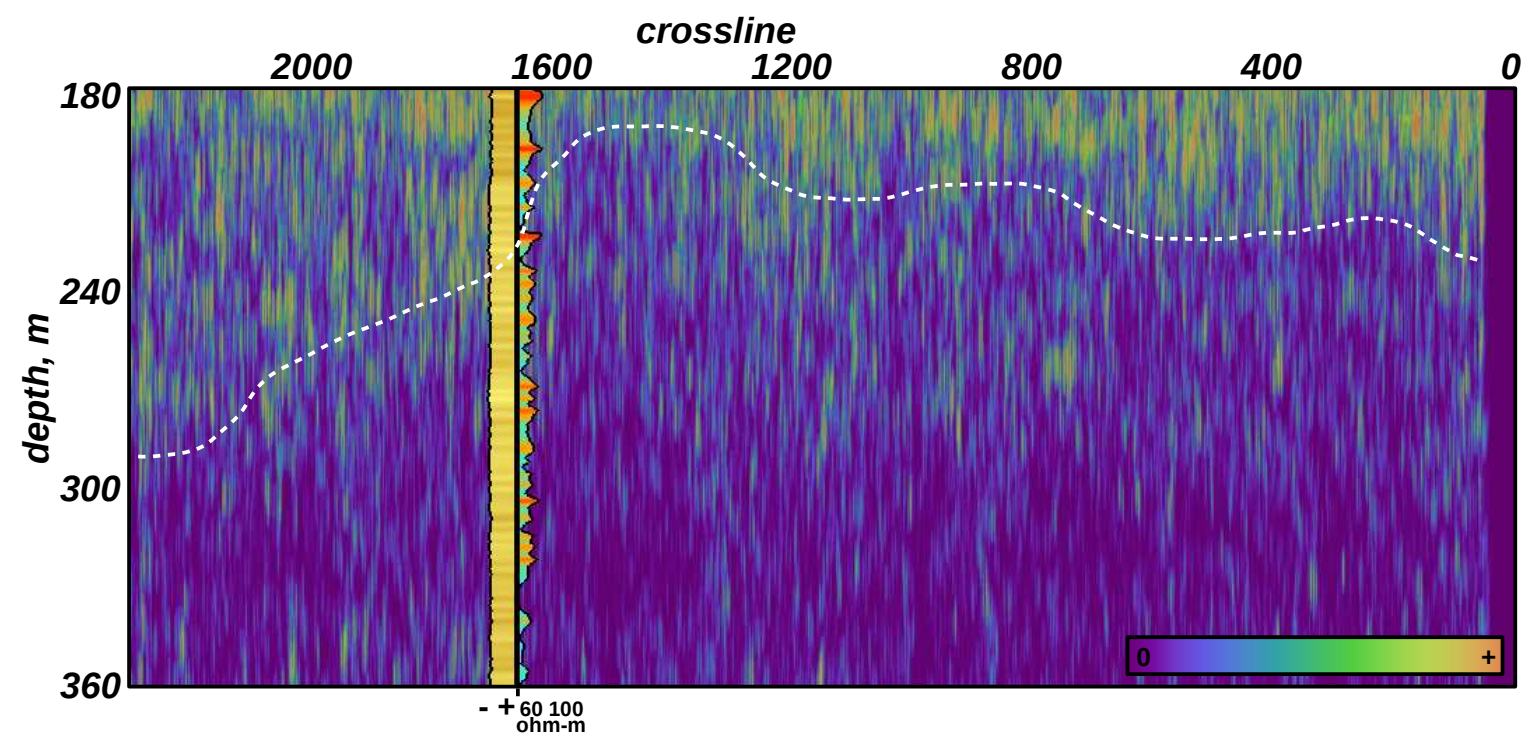

Figure 15: Inline 300 showing the diffraction energy attribute. The sections are overlaid by borehole logs projected from the actual position: spontaneous potential log (left, dark colors indicate more shale content) and electrical resistivity log (right). Dashed white outline denotes the boundary between upper high-diffractivity area and underlying low-diffractivity area.

Klokov et al. 


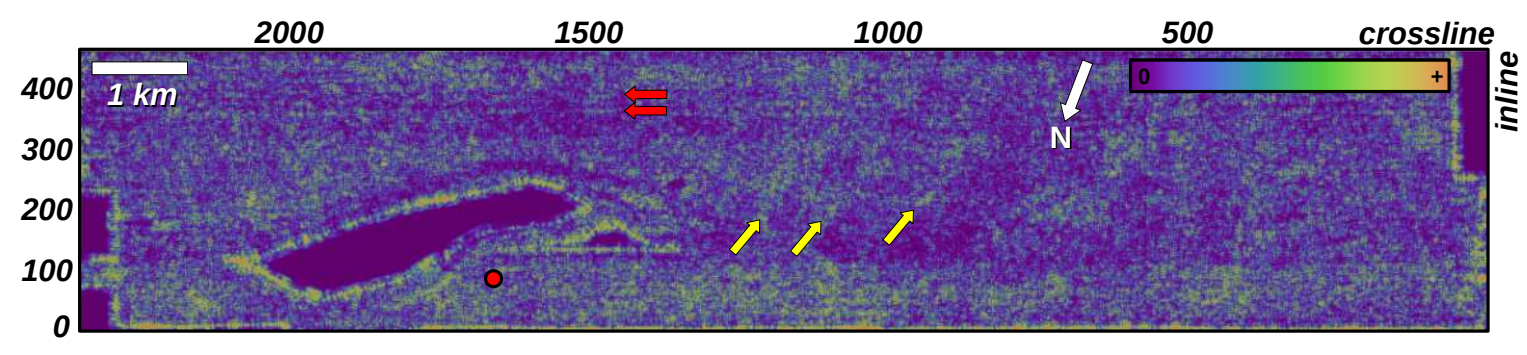

Figure 16: Depth slice from $300 \mathrm{~m}$ for diffraction energy attribute. Yellow arrows indicate subtle linear clusters associated with faults. Red arrows indicate acquisition footprint which appears prominent at that depth. Red dot locates a well in which the wireline logs were recorded.

Klokov et al. 